\title{
ANALISA SISTEM INFORMASI MASTER DATA OUTLET BERBASIS WEB PADA PT PINUS MERAH ABADI
}

\author{
Suwarto ${ }^{1}$ \\ Haryanto ${ }^{2}$ \\ Clara Agustin Afriyenis ${ }^{3}$ \\ Dosen STMIK Raharja Tangerang Jurusan Sistem Informasi ${ }^{1,2,3}$ \\ Jl. Jendral Sudirman No 40 Modernland, Tangerang \\ E-mail: suwarto@raharja.info ${ }^{1)}$, haryanto@raharja.info ${ }^{2)}$, clara@raharja.info $^{3)}$
}

\begin{abstract}
ABSTRAK
Pengiriman master data outlet merupakan peranan yang sangat penting bagi kelancaran jalannya suatu sistem penjualan yang berada di PT Pinus Merah Abadi, pengiriman master data yang masih mengandalkan sistem e-mail yang seringkali e-mail tersebut jarang terkirim dikarnakan adanya down sever e-mail yang sering terjadi akibat jaringan yang tidak stabil sehingga mengakibatkan terhambatnya pengirima master data outlet dari kantor pusat ket kantor cabang. Maka dari itu untuk mengatasi hal tersebut diperlukan adanya sistem master data berbasis web yang mempermudahkan master data outlet didapatkan tanpa harus menunggu adanya e-mail masuk dan khawatir akan adanya down server email dengan begitu master data outlet dapat di ambil langsung melalui website yang telah dibuat.
\end{abstract}

Kata kunci: e-mail, website, master data

\section{ABSTRACT}

Delivery master data outlet is a very important role for the smooth running of a sales system located in PT PinusMerahAbadi, sending master data that still rely on e-mail system that is often e-mail is rarely sent dikarnakan down sever e-mail that often Occurs due to unstable network resulting in inhibition of master data outlet from the head office of the branch office. Therefore to overcome it is required a web-based master data system that facilitates the master data outlet obtained without having to wait for e-mail entry and worried about the down mail server with the master data outlet can be taken directly through the website that has been made.

Keywords: e-mail, website, master data 


\section{PENDAHULUAN}

Evolusi peradaban manusia mengalami perubahan yang sangan signifikan pada tiap kurun waktu lamanya. Peradaban evolusi tersebut dimulai ketika awal manusia mengenal tulisan yang disebut dengan awal dari zaman sejarah, yang pada saat evolusi ini manusia mulai mengadakan beberapa penelitian tentang ilmu pengetahuanyang manfaatnya bisa dirasakan hingga saat ini. Dan pada akhirnya perkembangan ilmu pengetahuan dapat menghasilkan sebuah penemuan baru pada bidang ilmu elektronika yang dikenal dengan teknologi. Dengan demikian manusia dituntut untuk memiliki kemampuan untuk berkarya dan bersaing dengan manusia yang lain yang dilakukan secara interkontinetal. Dan hal ini kemudian dikela dengan fenomena global.

Akibat dari fenomena ini perusahaan-perusahaan membutuhkan tenaga kerja terampil yangdapat membawa sebua perusahaan tertentu berkembang dan dapat bersaing dengan perkembangan zaman, dan aspek perekrutannya mulai mendapatkan pandangan khusus, karenaproses perekrutan yang tidak sesuaidengankebutuhan perusahaan dapat menghambat laju berkembangnya perusahaan itu sendiri. Demikian yang terjadi pada PT Pinus Merah Abadi (PMA), dikarnakan banyaknya settingan data outlet dan discount promo yang tidak dapat di terima dari team Master Data Maintenance (MDM) kepada team Support memalui email yang membuat lamanya settingan diturunkan kembali ke area (cabang) dan tehambatnya proses settingan tersebut. Dengan melihat hal tersebut kita bisa menilai bahwa masih banyak permasalahan yang perlu dibenahi dalam sistem yang sedang berjalan pada saat ini.

Berdasarkan latar belakang tersebut, maka penulis bermaksud mengadakan sebuah penelitian pada kuliah kerja praktek yang diberi judul "Analisasi Sistem Informasi Master Data Outlet Berbasis Web pada PT. Pinus Merah Abadi”.

\section{RUMUSAN MASALAH}

Dari latar belakang diatas, maka dapat dilakukan perumusan masalah sebagai berikut:

1. Bagaimana prosedur pengiriman settingan outlet dan diskon promo PT Pinus Merah Abadi yang berjalan saat ini?

2. Bagaimana identifikasi terhadap kendala kendala pengiriman yang menghambat settingan outlet dan discount promo kepada team lainnya?

3. Apakah manfaat yang akan didapat dari penerapan secara sistem WEB atau secara email?

\section{TUJUAN PENELITIAN}

Dalam melakukan penelitian ini penulis memiliki beberapa tujuan diantaranya adalah sebagai berikut:

1. Untuk mengetahui sistem pengiriman settingan outlet dan diskon promo PT Pinus Merah Abadi yang berjalan saat ini.

2. Untuk identifikasi terhadap kendala kendala pengiriman yang menghambat settingan outlet dan discount promo kepada team lainnya.

3. Untuk mengetahui manfaat yang didapat dari penerapan secara Web dengan yang melalui email pada PT. Pinus Merah Abadi.

\section{METODOLOGI PENELITIAN}

Dalam metode penelitian Penyusunan ini penulis menggunakan beberapa metode pengumpulan data, diantaranya Metode interview/wawancara merupakan suatu metode pengumpulan data yang dilakukan dengan tanya jawab dengan pihak-pihak yang tekait. Pada penelitian ini penulis melakukan wawancara bersama stakeholder. Metode studi pustaka, metode ini merupakan metode yang digunakan untuk mendapatkan data dengan mempelajari data yang berhubungan dengan kerja lapangan yang berkaitan dengan sistem yang berjalan saat ini melalui sumber-sumber literature seperti buku,jurnal, paper,internet dan lain sebagainya. 
Data-data yang diperoleh daripenelitian kemudian diolah dan dianalisa terhadap sistem yang berjalan pada Sistem pengiriman data settingan outlet yang akan disesuaikan dengan metode penyimpanan WEB.

\section{LITERATURE REVIEW}

Berikut ini adalah penelitian yang telah dilakukan dan memiliki kolerasi yang searah dengan penelitian ini diantara lain:

1. Alvin Assianto Lemian.Dkk (2013) Penelitian yang berjudul "Aplikasi Ujian Online Pada Mobile Device Android" Aplikasi ujian online menggunakan koneksi internet untuk berkomunikasi dengan server. Aplikasi ujian online dibuat dengan menggunakan bahasa pemprograman java. Berdasarkan hasil pengujian, aplikasi ini dapat berjalan dengan baik pada smartphone dengan sistem operasi ini android versi 4.0 (Ice Cream Sandwich) ke atas dalam orientasi landscape.

2. Penelitian yang dilakukan oleh Lucy Meliana Septarini dengan judul "Analisa Sistem Informasi Pengolahan Berita berbasis Web Pada Surat Kabar ProTangerang" menjelaskan bahwa penelitian tersebut system tersebut belum dapat memberikan informasi secara cepat. Oleh karena itu melakukan perancangan pembuatan website agar ProTangerang dapat menerbitkan informasi secara cepat serta kebutuhan tersebut untuk ProTangerang dengan adanya webite ini.

3. Penelitian skripsi di STMIK Raharja yang dilakukan oleh Heru Sugiarto (2010), dengan judul "Perancangan Sistem Informasi Penerimaan Barang Berbasis Web pada PT. Aneka Komkar Utama”. Dengan adanya sistem yang terintegrasi dengan satu server web diharapkan mampu meminimalis adanya perbedaan antara stock bahan baku dengan order bahan baku sehingga dengan jelas input dan output bahan baku tersebut. Tapi dalam hal ini belum terdefinisi secara jelas bagian-bagian yang melakukan pengambilan bahan baku, sehingga dapat disimpulkan bahwa belum terorganisir bagian-bagian mana yang mengambil bahan baku tersebut. Dari sini penulis melakukan pengembangan sistem agar terdefinisi jelas bagian-bagian yang melakukan pengambilan bahan baku, sehingga user akan lebih mudah dalam pencarian data bagian mana saja yang melakukan pengambilan.

4. Penelitian skripsi di STMIK Raharja yang dilakukan oleh Indra Purnama (2010)dengan judul "Perancangan Sistem Informasi Persediaan Bahan Baku pada PT. Surya Siam Keramik". Penelitian ini diusulkan agar para pemimpin dapat mengetahui persediaan bahan baku sehingga kekosongan bahan baku bisa terhindarkan. Akan tetapi sistem ini masih kurang karena hanya memperlihatan stok akhirnya saja tanpa ada keterangan pemakaian atau pemasukan bahan baku tersebut. Dalam hal ini penulis melakukan pengembangan sistem agar sistem yang ada tidak hanya memperlihatkan stok akhirnya saja, jadi sistem ini akan dilengkapi dengan keterangan pemakaian dan pemasukan bahan baku yang ada di gudang, sehingga akan menghasilkan laporan stok yang lebih lengkap dan mempermudah dalam pencarian data.

\section{PEMBAHASAN}

\section{Analisa Sistem Yang berjalan}

Sistem yang berjalan pada PT Pinus Merah Abadi saat ini adalah pengiriman Master Data Outlet ( perkerjaan ) masih menggunakan sistem Email. Adapun penjelasan lebih rinci mengenai sistem yang sedang berjalan terdapat pada Unified Modelling Language (UML).

\section{Prosedure Sistem Yang Berjalan}

Prosedur pengiriman Master Data Outlet yang berjalan saat ini di PT Pinus Merah Abadi adalah mentahan Master Data Outlet yang diberikan dari team sebelumnya kepada team MDM yang akan dibuatkan Master Data Outlet dengan format .txt yang akan didownload ke sistem akan dikririmkan melalui email dan di terima olet team Support yang akan mengirimkan langsung kepada area masing - masing untuk didownload.

\section{Use Case Diagram Sistem Yang Berjalan}

Untuk menganalisa sistem yang berjalan, pada penelitian ini digunakan program Visual Paradigm for UML 6.4. Enterprise Edition untuk menggambarkan use case diagram, activity 
diagram dan squence diagram. Berikut adalah Use Case Diagram yang mewakili bagaimana system yang berjalan pada PT Pinus Merah Abadi

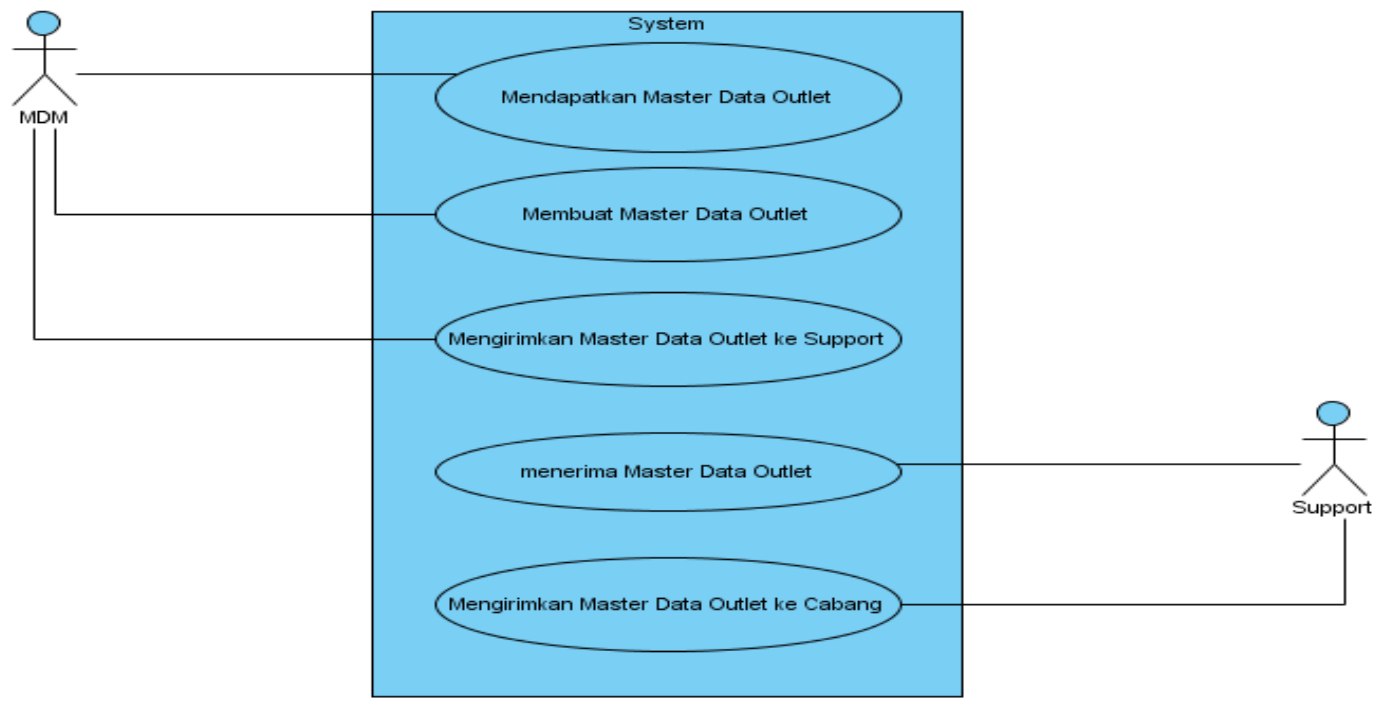

Gambar 1. Use Case Diagram

Berdasarkan pada gambar Use Case Diagram diatas terdapat:

1. 1 system yang mencangkup seluruh sistem yang berjalan pada PT Pinus Merah Abadi.

2. 2 actor, yang melakukan kegiatan, yaitu: MDM dan Support.

3. 5 use case, yang merupakan kegiatan yang dilakukan oleh actor - actor.

\section{Activity Diagram yang berjalan}

Activity Diagram ini untuk menggambarkan rangkaian aliran aktifitas baik proses bisnis maupun use case. Dapat juga digunakan untuk memodelkan action yang akan dilakukan saat sebuah operasi diksekusi dan memodelkan hasil dari action tersebut.

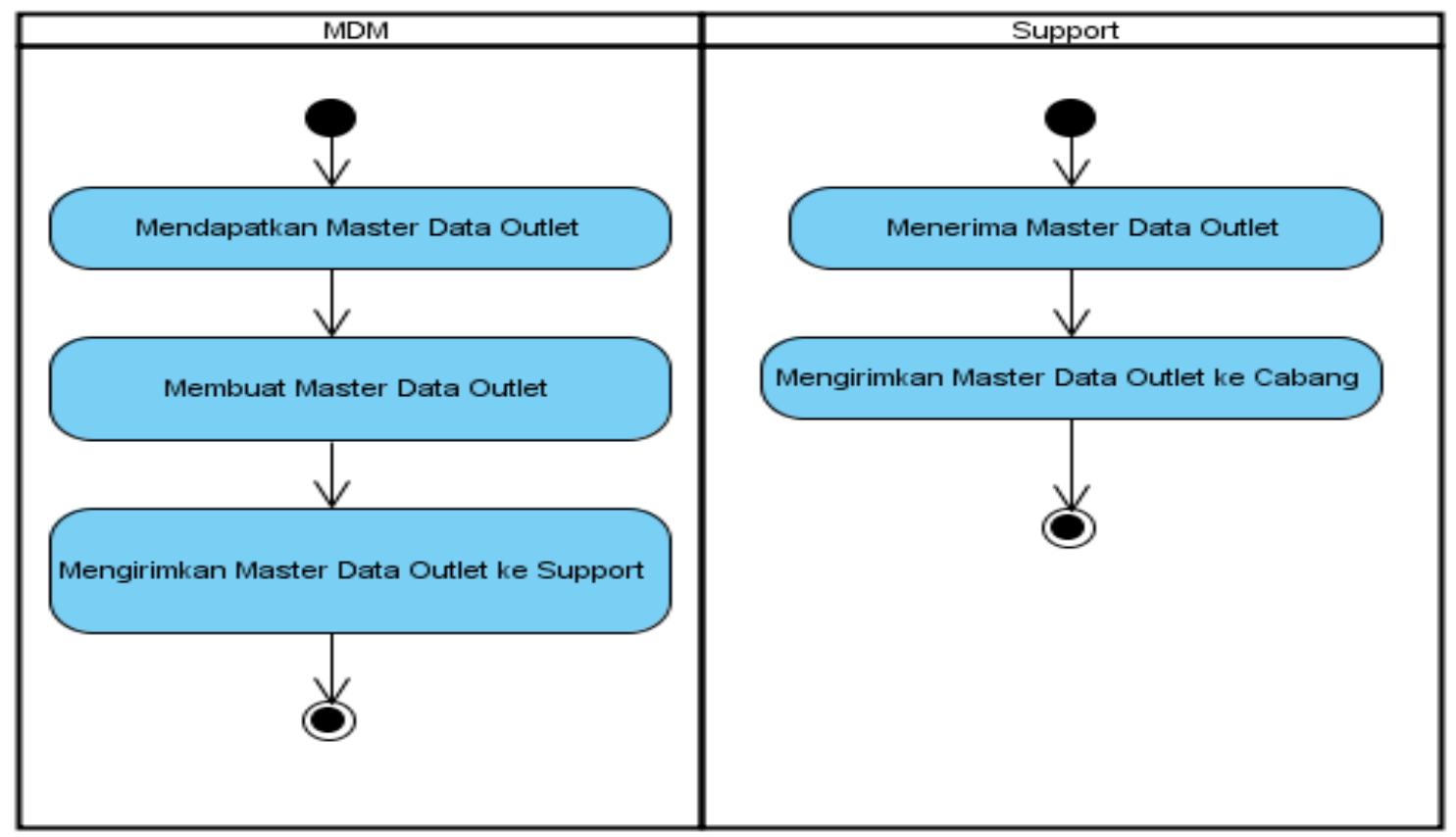

Gambar 2. Activity Diagram

Berdasarkan gambar Activity Diagram diatas terdapat:

1. 2 Initial Node, merupakan Objek yang mengawali kegiatan.

2. 5 Action, state dari sistem yang mencerminkan eksekusi dari suatu aksi.

3. 2 Activity Final Node, merupakan objek yang mengakhiri kegiatan. 


\section{Sequence Diagram Sistem yang Berjalan}

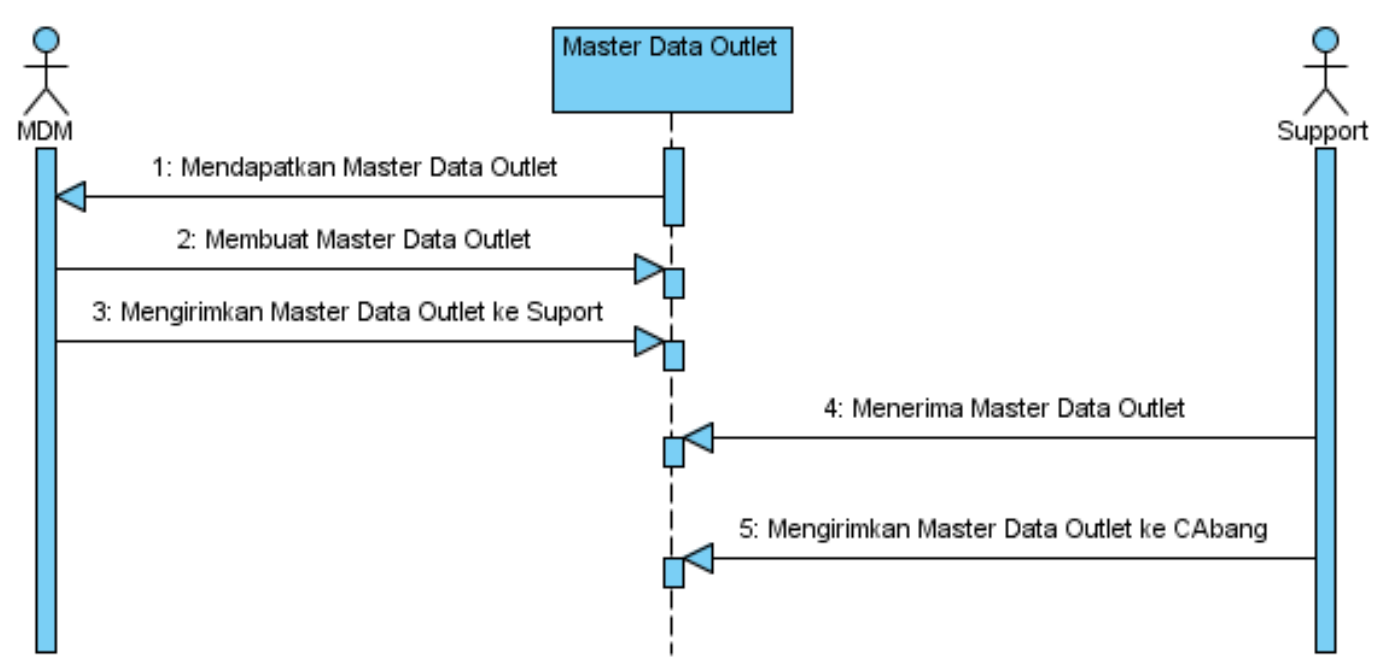

Gambar 3. Sequence Diagram

Berdasarkan gambar Quence Diagram diatas terdapat :

1. 2 actor, yang melakukan kegiatan, yaitu : MDM dan Support.

2. 1 Lifeline, merupakan antar muka yang saling berinteraksi.

3. 5 Mesage yang merupakan komunikasi antar objek yang memuat informasi informasi tentang aktifitas yang terjadi.

\section{Permasalahan Yang Dihadapi}

Permasalahn yang dihadapi adalah seringnya down email yang berakibat tidak sampainya Master Data Outlet sistem yang seharusnya diterima oleh team Support dari team MDM yang akan dikirimkan ke area, sehingga terjadinya banyak Master Data Outlet yang seharusnya sudah berjalan diarea tetapi Master Data Outlet tersebut belum juga di terima oleh team Support akibat email down yang mengakibatkan banyaknya email yang sudah dikirimkan tidak sampai pada email masing - masing team Support tersebut.

\section{Alternatif Pemecahan Masalah}

Dengan adanya masalah email yang tidak akan terkirim ke email support dikarnakan server email yang sering down sehingga dibuatlah alternatif pemecahan masalah atas kasus ini dengan dibuatnya penyimpanan Master Data Outlet bebasis website yang akan memudahkan team support untuk menerima Master Data Outlet dengan cepat tanpa harus khawatir tentang doen server email yang berakibatkan tidak diterimanya srttingan tersebut melalui email, dengan adanya penyimpanan berbasis website ini team support dapat mengambil secara langsung Master Data Outlet apa saja yang sudah dibuat oleh team MDM dan Master Data Outlet apa saja yang diperlukan oleh setiap area masing - masing.

\section{KESIMPULAN}

Berdasarkan hasil analisa dan penelitian yang dilakukanterhadap sistem pengiriman master data outlet pada PT Pinus Merah Abadi yang masih belum optimal dan perlu dikembangkan. Kemudian dari analisa yang telah dilakukan, terdapat 3 perumusan masalah yang sebelumnya telah dijabarkan di dalam Bab I. Berikut hasil analisa yang penulis peroleh mengenai jawaban dari rumusan masalah yang asa, yaitu :

1. Prosedur pengiriman Master Data Outlet dan discount promo yang berlaku pada PT Pinus Merah Abadi masih mengandalkan pengiriman melalui media e-mail. 
2. Kendala tidak sampainya Master Data Outlet ke team lainnya dikarnakan seringnya e-mail server down yang mengakibatkan lamanya proses pengiriman master data tersebut.

3. Dengan adanya Master Data Outlet berbasis Web ini dapat diharapkan seluruh Master Data Outlet dapat diterima dengan mudah oleh team lainnya tanpa harus menunggu e-mail diterima.

\section{DAFTAR PUSTAKA}

[1] Sutabri, Tata. 2012. Konsep Dasar Informasi. Yogyakarta: Andi

[2] Yakub. 2012. Pengantar Sistem Informasi, Yogyakarta: Graha Ilmu

[3] Sutarman. 2012. "Buku Pengantar Teknologi Informasi". Jakarta: Bumi Aksara

[4] Mude, Anastasia. 2009. "Analisa Sistem Informasi Penilaian KKP/TA/SKRIPSI Berbasis Web Pada Perguruan Tinggi Raharja". Laporan KKP. Perguruan Tinggi Raharja.

[5] Oktabia, Dwi 2014 "Analisa Sistem Informasi Absensi Pegawai Pada SMK Pancakarya Tangerang”. Laporan KKP. Perguruan Tinggi Raharja. 